Revista de la red interuniversitaria de estudios sobre las literaturas rioplatenses contemporáneas en Francia

$13 \mid 2015$

Nuevas experiencias editoriales y literaturas

contemporáneas

\title{
El demonio de la edición
}

\section{Miguel Ángel Petrecca}

\section{OpenEdition}

Journals

Edición electrónica

URL: http://journals.openedition.org/lirico/2047

DOI: 10.4000/lirico.2047

ISSN: 2262-8339

\section{Editor}

Réseau interuniversitaire d'étude des littératures contemporaines du Río de la Plata

\section{Referencia electrónica}

Miguel Ángel Petrecca, «El demonio de la edición », Cuadernos LIRICO [En línea], 13 | 2015, Puesto en línea el 15 diciembre 2015, consultado el 21 abril 2019. URL : http://journals.openedition.org/ lirico/2047 ; DOI : 10.4000/lirico.2047

Este documento fue generado automáticamente el 21 abril 2019.

\section{(c) $)(9)$}

Cuadernos LIRICO está distribuido bajo una Licencia Creative Commons Atribución-NoComercialSinDerivar 4.0 Internacional. 


\title{
El demonio de la edición
}

\author{
Miguel Ángel Petrecca
}

1 Hojeando distraídamente la agenda de una revista de distribución gratuita del metro de París, me detuve de repente en el anuncio de un evento que tenía lugar esa semana en una de las universidades de la capital. El nombre de uno de los participantes (un científico norteamericano) me sonaba : estaba seguro de que lo había escuchado en otro lado, hacía mucho tiempo, aunque no podía decir cuándo y dónde. Pasé el día tratando de hacer memoria, y cuando volví a casa lo primero que hice fue buscar en internet, hasta que recordé la anécdota con la que estaba asociado : una conversación, una noche del invierno de 2005, en Bahía Blanca. Era Gustavo López, editor de Vox, el que esa noche había hablado de Jacobson (el científico) y de su proyecto : un libro electrónico con páginas de papel electrónico flexibles, que uno podría hojear y subrayar, y que sería capaz de cargar una biblioteca entera. Jacobson lo llamaba con justeza "El libro final". Para Gustavo, "El libro Final" era una prueba más de que al libro de papel le quedaban pocos años, y junto con él también a los editores, es decir a los mediadores, cuya función pronto se volvería superflua. El rol del editor, sugería el editor esa noche, era darle la bienvenida al fin de su propio rol : preparar, en plan de partero de la historia, su propia desaparición.

2 En el invierno de 2005 Gog y Magog tenía menos de diez títulos publicados. Habíamos lanzado nuestros primeros títulos menos de un año atrás, en octubre de 2004, en una presentación en el MALBA, punto final de un largo proceso de al menos dos años de trabajo. Con Laura Lobov nos habíamos conocido en el taller de poesía de Arturo Carrera, a fines de los 90. Nos habíamos cruzado también en la Facultad de Letras, pero en el taller fue donde nos hicimos amigos. Más tarde, coincidimos en otro taller de un año que organizaba la Fundación Antorchas. Ahí conocimos a Julia Sarachu.

3 Eso fue por el año 2000. Antes del 2001, seguramente. Comenzamos a pensar en la idea de la editorial entre fines del 2002 y principios del 2003. Éramos cuatro, rápidamente quedamos tres. Reuniones en bares de Congreso, en la casa de Laura de Congreso, en mi casa de Congreso, en bares de Plaza Italia. Muchas de esas reuniones, las primeras, sólo para elegir el nombre. Otras tantas para tratar de entender qué es lo queríamos hacer. Publicar nuestros libros, en principio. Porque además de haber formado parte del taller, 
los tres teníamos en común eso : el hecho de tener un libro entre las manos. Lo habíamos trabajado en el taller, habíamos leído en los ciclos de poesía de aquel entonces (Zapatos rojos, La voz del erizo), publicado poemas sueltos en revistas. Todo eso le daba a esos libros inéditos un contorno fantasmagórico, una existencia supuesta. Cuando uno llegaba a ese punto, por ese entonces, podía recurrir a algunas de las varias editoriales que publicaban poesía joven. Las más interesantes eran las que habían surgido entre mediados y fines de los 90, como Siesta, Ediciones del Diego o Vox. Había otras, muchas otras, como Amadeo Mandarino, Belleza y Felicidad, Ediciones del Dock, Alción, Bajo la luna, Tierra Firme, pero el catálogo de poesía joven de esas tres era el más atrayente. Cada una representaba además una tipología de editor o de editorial. De un lado, Siesta, con sus libros extremadamente pensados desde el diseño, isbn, arte de tapa, contratapas, prólogos: libros que sólo se diferenciaban de un libro estándar en la cuestión del tamaño, de la miniatura que coqueteaba con el libro objeto. Siesta era una editorial anfibia: podía colarse en las librerías, en donde su carácter de cuasi objeto y su novedad le aseguraban una exposición privilegiada en el mostrador, pero también circulaba en el circuito paralelo de la poesía (ferias, lecturas, etc.). Del Diego, en cambio, representaba un concepto diferente, desde el proceso mismo, pues los libros (las plaquetas) se hacían íntegramente en la casa de los editores : libros diseñados e impresos caseramente, abrochados uno por uno. La colección llevaba el sugestivo nombre de "Antología general de la joven poesía argentina", y su circulación estaba más limitada al circuito de la poesía. Vox era más ambigua, alternando libros y plaquetas, pero a su vez se diferenciaba de las otras, dirigidas por poetas-editores, en que su director Gustavo López era un editor puro.

Siempre pensé que el proyecto de Gog y Magog tenía mucho que ver con la atmósfera post 2001, con algo de ese momento que te movía a hacer cosas. Gog y Magog es, en ese sentido, una editorial decembrista. Para 2003, además, muchas de las editoriales que nos gustaban habían empezado a declinar. Del Diego se había disuelto, enredada en sus propias internas y fundida por un subsidio del gobierno que los había hecho gastar por adelantado un dinero cuyo retorno, devaluado rápidamente por la inflación, se demoraba. Siesta comenzaba ya a mostrar signos de agotamiento, Amadeo Mandarino había virado hacia una perspectiva más introvertida, Vox estaba muy lejos. El punto de partida era editar nuestros libros. ¿Pero si fuera al revés? ¿ Si en vez de haber creado la editorial para publicar nuestros libros, habíamos escrito para poder crear una editorial ?

No me recuerdo haciéndome entonces la pregunta esencial, es decir, preguntándome qué significaba editar un libro: el significado de editar, como el de leer, parecía estar adecuadamente cubierto por el acto mismo que lo señalaba. Editar un libro era antes que nada elegir un texto y fabricar un objeto. Hasta ahí para mí resultaba claro. Luego, estaba la presentación. Eso también era obvio, obvio en el sentido de natural, de algo que se da por sentado. ¿Pero por qué era tan natural ? ¿Qué significaba presentar un libro ? ¿Se trataba de una celebración, de un bautismo, de un ritual por el cual el objeto y la editorial adquirían un estatuto real? En todo caso, en nuestro caso la presentación cumplía, además, una función económica evidente: en una presentación podíamos vender más ejemplares de un libro de lo que venderíamos en varios meses. ¿Y después? Después estaba ir a ferias y lecturas, enviar el libro a algunas librerías, a ciertas personas. ¿ $Y$ después? 
6 Se podría contar la historia de Gog y Magog a través de las sucesivas respuestas a ese después. O se podría contar a través de la evolución en su modo de producción. El modo mixto (entre artesanal e industrial) y un poco al tanteo de los primeros cinco libros : tapas impresas en offset en una imprenta en Colegiales, interiores (fotoduplicación) en otra imprenta en Congreso, intercalado manual en mi casa (a lo largo de varias reuniones), encuadernado binder, refilado a cargo del encuadernador. La segunda, la tercera tanda, la cuarta tanda, enteramente en imprenta : interior en offset digital, tapas en offset, cosido. La quinta en otro imprentero, problemática, con interiores en offset de verdad, vegetales corregidos apresuradamente en un local que el imprentero había tomado prestado de unos compañeros de militancia (fragmentos sueltos de la izquierda a punto de converger hacia el imán del kirchnerismo). La siguiente, el retroceso táctico, fotoduplicadora comprada por internet, resmas apiladas en un cuarto, una semana entera imprimiendo. La etapa de la fotoduplicadora, dentro de la historia de la editorial, es algo así como el Período Especial. Yo me fui a China en ese momento y cuando volví un año después la fotocopiadora seguía ahí. Llegamos a imprimir otras dos tandas. La última, la semana de la muerte de Kirchner. Luego vendimos la fotoduplicadora y volvimos a la imprenta. En el medio, nuestros libros también habían cambiado: lentamente se estandarizaron, se volvieron más prolijos y profesionales : les creció una solapa, les surgió una contratapa, cambiaron la cartulina por el papel ilustración, la sobriedad y el vacío original fue reemplazada por fotos, las fotos sacadas de internet por otras elegidas por un curador (Akira Patiño), el tamaño de bolsillo por otro más estándar de 14x20.

7 La historia de su catálogo : la de las sucesivas infracciones a un estatuto inicial, en el que estaba tácitamente escrito el objetivo de publicar poesía argentina, la de los jóvenes y la de los que ya estaban dejando de serlo por ese momento. Pero luego, también, poesía latinoamericana (Maquieira, Augusto de Campos, Morábito, Costa), y luego, también y sobre todo traducciones. Con estas sucesivas "infracciones" al estatuto inicial, el concepto de la editorial se fue repensando y ampliando. Gog y Magog empieza en el 2004 como una editorial inspirada en experiencias de los 90 pero se convierte con el tiempo en otra cosa. Imperceptiblemente, como describe Mark Strand en uno de los poemas de la antología que publicamos: "Nadie se da cuenta/pero la arquitectura de nuestro tiempo se está convirtiendo lentamente en la arquitectura del futuro". Lo que hace de Gog y Magog una editorial de los 2000 no es tanto la presencia de poetas del 2000 en el catálogo, sino el hecho de proponer una experiencia editorial novedosa. Esta novedad, esta diferencia está en la búsqueda de una síntesis ambiciosa (entre poesía en castellano y traducciones, poesía argentina y latinoamericana, joven y no tan joven), y en el deseo ser sostenibles sin renunciar al núcleo de nuestra identidad como editorial de poesía.

8 Antes de tener una fotoduplicadora en casa, mucho antes en realidad, antes de Gog y Magog incluso, tuve una guillotina. Una de esas guillotinas viejas de hierro puro, con la que se puede cortar una resma limpita. Pesaba mucho, y para subirla por la escalera hasta el tercer piso del ph donde me había mudado a fines de 2001 hicieron falta cuatro personas, dos de ellos profesionales. El recuerdo de la guillotina me muestra que había empezado a pensar en hacer libros antes siquiera de pensar en hacer una editorial. Incluso, por esa misma época, tomé un par de clases con una persona que me enseñó lo básico de cómo coser los cuadernillos. El resultado de todo eso, de la guillotina y de las 
clases, de la fascinación con la imagen del editor-poeta-artesano, fue un par de libritos en tapa gris : una edición de un solo ejemplar de mi propio libro, y un par de ejemplares de La Tirana del chileno Diego Maquieira. También por esa época me compré una abrochadora de brazo largo, indispensable para una serie de proyectos de plaqueta que nunca salieron de la etapa de proyecto. Cuando me mudé la guillotina fue a parar al sótano de un amigo. Estuvo ahí varios años antes de ser vendida. La fotoduplicadora igual, poco después. La abrochadora sirvió para abrochar algunos libros de la editorial Spiral Jetty. Cuando Spiral Jetty cerró, la abrochadora volvió a mí. Ya no era la misma abrochadora. Era una abrochadora con un pasado. El caso de Spiral Jetty es particularmente interesante : una editorial ready-made, en dos sentidos: a nivel de la concepción, pues se trata de una editorial casi conceptual ; pero también en el sentido de la fabricación inmediata, de la posibilidad de lograr máximos efectos editoriales a partir de mínimos recursos : una impresora y una abrochadora. Como del Diego y otras editoriales similares, Spiral Jetty se encuentra en el extremo liviano de la experiencia editorial: editoriales a las que la sencillez del método les permite moverse rápido, publicar unos pocos ejemplares y ampliar su catálogo sin demasiadas preocupaciones. En el otro polo, están las editoriales pesadas. Una editorial pesada avanza más despacio, su catálogo no puede ampliarse a la velocidad de una editorial liviana, lleva como lastre la necesidad de administrar los recursos. Pero los efectos de cada una de esas decisiones pueden ser más intensos, más amplios. Entre fines de los 90 y los 2000, la introducción de la imprenta digital amplió el espectro de posiciones posibles entre ambos polos. Alejándose del polo liviano por su vocación de hacer libros en lugar de plaquetas, una editorial pequeña puede sin embargo buscar equilibrios frágiles, acercarse y alejarse de cada polo dependiendo del proyecto. Ser más liviana, por momentos, para crecer más rápido ; ser más pesada, de golpe, para retumbar más fuerte.

Dos de las cosas que más me gustan de ser editor : escribir contratapas y ver los libros desplegados sobre una mesa. Sobre todo esto último. Nunca vi los libros de Gog y Magog desplegados sobre la totalidad de la mesa de una librería, como recuerdo haber visto los de Hiperión en cierta librería de Corrientes, a fines de los 90. Mientras espero que llegue ese día me complazco con desplegarlos en ferias y lecturas, sobre caballetes, mantas, manteles. Me gusta poner los libros a distancia equidistante uno de otro, en hileras parejas, ordenadas, separadas por calles. Despliego los libros sobre la mesa como las cartas de un mazo, como si estuviera jugando un solitario. Un día tuve un sueño relacionado con esto, del que no me acuerdo demasiado los detalles, pero del que me desperté de repente convencido de la similitud entre un libro y una lápida, entre la imagen de los libros desplegados sobre una mesa y la imagen de un cementerio. Y pensé después que en cada libro publicado también hay algo de despedida, algo de duelo, algo como el entierro de una voz. El editor es una especie de sepulturero. De ahí también la dificultad del libro electrónico : no se puede hacer duelo si no está el cuerpo.

Entonces, está por un lado el editor-artesano. El editor artesano es en parte una novedad de los 90, y prolifera de manera sorprendente en los 2000, al calor de la FLIA (Feria del 
libro independiente y autogestiva). El editor artesano imprime y diseña sus libros, los cose, los refila, habla apasionadamente del gramaje del papel. El editor artesano tiene, a veces, una ideología asociada con su condición de artesano. Luego está el editor un poco desprolijo pero altruista, en la línea del editor de izquierda estilo Mangieri : el editor que fabrica su propia leyenda y al que a su muerte se le escribe una necrológica emocionada: "Quería ser un soldado pero fue un soldador. / Bajaba la máscara de acero y trabajaba durante la noche / uniendo los destinos de personas / que se rechazaban como órganos implantados." (Fabián Casas). Está el editor que tira la piedra y esconde la mano, el editor anónimo, que ve la edición como un complot: como el editor de un pequeño libro de Raymond Roussel que alguien me pasó una noche, a comienzos de los 2000. El editor que se toma literalmente el sentido de la palabra colección y acumula libros con la manía de un coleccionista. El editor glaneur. El editor que edita para siete personas y solamente para siete personas. El editor que se limita a cumplir una misión y, una vez cumplida, se retira (Fogwill, Ediciones La Tierra Baldía), es decir, el editor que no está habitado por el demonio de la edición. Salvo este, todos los demás están invariablemente habitados o son visitados con frecuencia por el demonio de la edición.

\section{AUTOR}

\section{MIGUEL ÁNGEL PETRECCA}

Poeta y fundador del sello Gog y Magog 